\title{
El objeto en el ilusionismo
}

\author{
( Miguel Nigro \\ Universidad Nacional de las Artes, Argentina \\ miguelnigro@fibertel.com.ar
}

Fecha de recepción: 8/11/2019. Fecha de aceptación: 16/11/2020.

La finalidad de este análisis es proponer una inquietud investigativa hacia la práctica del ilusionismo. De todos sus componentes, selecciono el objeto como muestra testigo pasible de ser cotejado con otras actividades artísticas basadas en lo objetual.

La utilería mágica presenta, en sus aspectos materiales, un grado de estandarización poco frecuente en otras disciplinas artísticas. Objeto y truco suelen considerarse como la unidad indivisible de la magia. Esta fórmula promueve una constante repetitiva que es modificada apenas por las cualidades histriónicas del ilusionista. Es posible demostrar que las cosas que intervienen en la magia pueden ser, a través de un análisis crítico y comparativo, valoradas por su dimensión estética y significativa como la singularidad del acto mágico.

PALABRAS CLAVE: OBJETO, ILUSIONISMO, MAGIA, TEATRALIDAD, MANIPULACIÓN.

\section{The Object in the Illusionism}

The purpose of this analysis is to propose an investigative concern towards the practice of illusionism. Of all its components, I select the object as a sample that can be checked against other artistic activities based on the objectual.

Magic props present, in their material aspects, a degree of standardization rare in other artistic disciplines. Object and trick are usually considered as the indivisible unit of magic. This formula promotes a repetitive constant that is modified only by the histrionic qualities of the illusionist. It is possible to demonstrate that the things involved in magic can be, through a critical and comparative analysis, valued for their aesthetic and significant dimension as the uniqueness of the magical act.

KEYWORDS: OBJECT, ILLUSIONISM, MAGIC, THEATRICALITY, MANIPULATION. 


\section{Introducción}

La ilusión en el teatro presenta una ficción con apariencia de realidad, crea un mundo de referencia que se ofrece como posible y que bien podría ser el mundo de quien lo observa. El ilusionismo, como manifestación espectacular basada en el engaño, amplía la ilusión teatral. No sólo ofrece como verdadero aquello que es ficción, sino que redobla la condición ilusoria haciendo real lo imposible. Acontece algo que no encuentra explicación tanto en la representación ficcional como en el universo extrateatral. Lo fantástico no se aísla en lo soñado sino que se hace evidente y demostrable. La experiencia mágica, en su grado óptimo, provoca en el espectador tal nivel de interferencia en la secuencia pragmática de los eventos creíbles, que lo conduce al pasmo.

La naturaleza del género ilusionismo es imprecisa y difusa. Confluyen un conjunto de principios que recrean artificialmente lo ilógico del universo imaginario: faquirismo, hipnosis, telepatía, embuste, invulnerabilidad, prestidigitación, espiritismo, pseudofísica y juegos de apuesta, entre otras manifestaciones.

Para lograr su fin, en todas sus variantes, la magia diseña estrategias y técnicas, crea un personaje arquetípico, ${ }^{1}$ define disciplinas internas y construye objetos.

Los componentes de la escena -sujeto, objeto y espacio- se combinan solidariamente en función del resultado extraordinario. El fenómeno se potencia cuando el espectador, en lógica desventaja, atribuye al ilusionista una elevada cuota de poder. En esta relación asimétrica los objetos asumen el rol de meros accesorios escénicos. Si bien el ilusionista es el fundamento espectacular de la escena y el espacio es la materia maleable, son las cosas las que ordenan la fisicalidad del misterio.

La esfera cósica encuentra en la ilusión otro destino cargado de ambigüedad. La definición por oposición como verdadero o falso, original o duplicado, real o virtual, se vuelve dudosa e insuficiente. Tanto el emisor como el receptor anclan su atención, desprovista de ingenuidad, sobre el objeto. El espectador, activando plenamente sus facultades y competencias, se esfuerza por interpretar correctamente al objeto y su devenir espacial, aunque es forzado a sobreinterpretar la situación. El ilusionista frustra discretamente la mirada radiográfica del público mediante la construcción discursiva, el sentido de oportunidad y el uso apropiado del objeto en el contexto espacial.

El objeto es el punto inicial de convergencia de dos voluntades, se configura a modo de interface primaria no verbal. Es la plataforma inerte de la comunicación mágica.

Es pertinente profundizar una categoría singular de objetos propios del ilusionismo o provenientes de campos heterogéneos, devenidos en su función mágica, que generan una expectativa ausente en el universo de utilería teatral.

En el lenguaje teatral, el objeto superó su pasividad decorativa y se articuló con la escenografía configurando sistemas lúdicos, engranajes y abstracciones. Fue promovido al rango de personaje y trascendió el límite nítido entre lo humano y lo no humano.

Para la investigación actual en arte, los objetos son motivo suficiente de especulación y estudio, producen teorías. Son categorizados como objetos animados, más allá de la lógica del títere y tratados como muestra de laboratorio a las cuales se les aplica métodos experimentales. Los objetos, hibridados con el sujeto, perfilan

1. El mago o ilusionista tal como lo identificamos en la actualidad -personaje de frac, galera y bastón, que realiza actos asombrosos con objetos cotidianos, animales o grandes aparatos- es una figura teatral consolidada en el siglo XIX, cuando la magia se formaliza como arte del entretenimiento. 
nuevos sistemas bio-objetuales en donde el actor se fusiona con las cosas para formar un nuevo artefacto viviente. El tecno-objeto que resulta de la unión de lo objetual y la tecnología, el cyborg o criatura compuesta por elementos orgánicos y dispositivos cibernéticos, la realidad aumentada que ofrece una experiencia interactiva al usuario a partir de la realidad física y el soporte virtual, plantean nuevas complejidades escénicas.

En pocas ocasiones, el desarrollo de la práctica y las investigaciones del teatro de objetos fueron considerados una valiosa fuente conceptual para el tratamiento del objeto en el ilusionismo. El objeto mágico se actualiza superficialmente con los requisitos que la moda demanda. Formas, texturas y colores son adoptados, imitados y trasladados como meros aspectos modernizantes.

Frente a este vértigo contemporáneo, la utilería mágica permanece en un status inicial de cosa, de accesorio inteligente, de partícipe necesario, improductivo para la reflexión teórica y para la indagación estética.

El estado de vacancia permite iniciar una investigación formal que revincule el objeto, fundamento de la ilusión, con el sujeto y el espacio.

\section{El objeto}

Para abordar el tema, es necesario aproximarse a una definición de objeto, o al menos focalizarlo por sus rasgos distintivos.

Objeto significa, en general, lo contra-puesto según el Diccionario de Filosofía Abreviado de José Ferrater Mora (2000: 260). El objeto es definido como término multívoco que alude, por una parte, a lo contrapuesto, lo opuesto al sujeto, y, por otra parte, al objeto como lo que es pensado, lo que forma el contenido de un acto de representación, independientemente de su existencia real. Considerando lo ilimitado de los objetos, el autor los divide en cuatro grupos: objetos reales, objetos ideales, objetos cuyo "ser" consiste en el valer y objetos metafísicos.

Para el desarrollo que me ocupa es de utilidad la primera categoría mencionada: "Objetos reales que poseen realidad en sentido estricto. En ellos se hallan incluidos los objetos físicos y los objetos psíquicos. Las notas de los primeros son la espacialidad y la temporalidad. Las de los segundos, la temporalidad y la inespacialidad" (2000: 261).

Me detendré en los objetos físicos, proyectados, diseñados y fabricados para un fin y con razón suficiente que justifique su presencia. Objetos logrados a través de un proceso productivo, objetos artificiales que se diferencian de las cosas producidas por la naturaleza. Sería inapropiado designar la rama de un árbol como objeto, a menos que sea señalada como utilitaria, convirtiéndola en perchero.

Un aspecto que fundamenta lo objetual es la dimensión, la cual debe facilitar la actividad manual. El exceso o defecto de un tamaño adecuado, visible y asible, que dificulte su normal manipulación, ubica al objeto fuera de la categoría específica.

Lo funcional se presenta como condición obligatoria del objeto, un reflejo automático nos advierte que lo que se muestra como materia configurada a través de la intervención humana, industrial o artesanal, se produjo para satisfacer una necesidad de uso. Es funcional un utensilio en tanto sirve para algo, colabora en una acción y se convierte en complemento o extensión del sujeto. En última instancia el objeto denota siempre una función. 
El objeto también posee atributos simbólicos que lo asimilan a un sistema de pertenencia. Por ejemplo, una lapicera, cuya función es graficar (escribir, dibujar, garabatear, etc.), altera su valor simbólico si está bañada en oro y pertenece a una colección. La lapicera dorada connota, entre otras cosas, lujo, institucionalidad y riqueza. Su materialidad la distingue de otras lapiceras, como por ejemplo una de plástico, cuyas connotaciones serán otras. Los atributos físicos de la lapicera la ubican en un contexto socio-cultural determinado y codificado.

El valor simbólico, de todas maneras, vuelve a poner el acento en la funcionalidad. La conducta corporal cambia a partir del valor del objeto. En el ejemplo de la lapicera bañada en oro, el comportamiento manual, al momento de escribir, puede estar modificado por la misma razón valorativa. El cuidado manipulativo no se ejerce de la misma manera que ante el bolígrafo de plástico.

Por lo tanto, el objeto es la reconfiguración, coherente e inteligible, impuesta por la cultura humana a toda materia prima, natural o sintética, cuya intención proyectiva se valida por el servicio prestado al sujeto. El objeto comunica a través de su función y valor un mensaje prospectivo interpretado a través un código conocido y compartido por la comunidad de usuarios.

La sociedad industrial y moderna produce objetos en serie, los cuales se distribuyen masivamente, generando una particular relación entre objeto y sujeto en tanto consumidor, poseedor y acumulador de cosas. La maquinaria productiva capitalista instauró un sistema basando su valor en la relación coste-beneficio. La producción descontrolada de objetos se valida por la acentuada voluntad de consumo, promovida como necesidad por el mismo circuito, y así el sistema se realimenta vertiginosamente.

Los objetos irrumpen, inundan y completan artificialmente el paisaje humano. Estas condiciones colaboraron para que el teatro cree prácticas singulares y complejas, donde el objeto se obstina en permanecer como objetualidad pura, como cosa infinitamente extraña y persistente.

\section{Teatro y animación de objetos}

A partir de las vanguardias del siglo XX, el objeto abandona su posición utilitaria, decorativa y servil y se instala como metáfora expresiva en las artes visuales y teatrales. No se conforma con el rol de cosa representada y se hace ostensible a través del collage, el assemblage y el ready-made e ingresa como forma más o menos antropomorfa, a medio camino entre el títere y la cosa, en el teatro de animación.

Las variables contemporáneas aplicadas al objeto teatral son extensas tanto en procedimientos como en significado. Estudios procedentes, sobre todo, del teatro de animación, de manipulación, de formas animadas, desarrollan perspectivas novedosas que replantean la objetualidad teatral. Espectáculos montados sobre la base de un lenguaje que integra, total o parcialmente, al sujeto producen especulaciones teóricas que colaboran con el desarrollo de una práctica compleja. Nuevos modos de hacer, comunicar, percibir, crear y compartir lo objetual, a través de metodologías interdisciplinarias y actividades formativas, expanden el campo teatral.

Nuestra región es dinámica y fecunda en lo referente a creación, investigación, pedagogía y difusión de este género relativamente nuevo. Algunos representantes locales dejan constancia de sus experiencias en publicaciones que profundizan la teoría que la práctica propone. Es el caso de Ana Alvarado, por citar un ejemplo, y la publicación reciente del libro Cosidad, Carnalidady Virtualidad. Cuerpos y objetos en la escena (UNA, 
2018), que es el resultado del proyecto de investigación dirigido por la propia Alvarado e integrado por artistas, estudiantes y docentes de la carrera de posgrado Especialización en Teatro de Objetos, Interactividad y Nuevos Medios de la UNA (Universidad Nacional de las Artes). En la introducción se explicitan los fundamentos

Buscamos establecer que existe una obra artística en el país que expresa la relación Cosidad, Carnalidad y Virtualidad en un modo nuevo, y que se presenta en el circuito que la recibe: teatros, museos, fundaciones, sin sentirse definitivamente parte de ninguno, pudiendo fluctuar de una expresión a otra, sin buscar ser conclusiva, muy cercana al cuerpo del propio artista y vinculada con lo objetual en modos diversos (Alvarado, 2018: 7).

El propósito de elaborar una definición, vinculando lo real y lo virtual en tanto espacio, objeto, sujeto y práctica, revela un compromiso ético y estético de los creadores que dan cuenta de las implicancias e irradiaciones que genera el objeto en escena. Esta visión, entre otras, podría aportar una perspectiva ampliatoria al objeto para la magia, considerándolo, en primera instancia, un objeto teatral manipulado.

La investigación actual dirigida al teatro de objetos, es un referente central en el intento de relocalizar el objeto mágico en tanto:

" Potencialidad expresiva y estética

"Singularidad real-virtual

" Participación interactiva

» Recepción de nuevas tecnologías

Los objetos mágicos portan una promesa, que en definitiva tienen como misión, que es la de reencantar la escena teatral y la cotidianeidad del universo material.

\section{Objeto e ilusionismo}

La producción específica del ilusionismo se centra actualmente en proyectar, elaborar, construir y comercializar objetos que satisfacen algunos de los principios mágicos: aparición-desaparición, transposición, restauración, penetración, transformación, levitación, adivinación y características antinaturales. Dispositivos destinados a provocar inevitablemente lo inesperado, diseñados para causar efectos que no se pueden precisar con la lógica racional.

Vale aclarar que no todos los objetos cumplen con tan elevado fin ilusorio. Me refiero aquí a los que gozan de cierta historicidad que los posiciona como clásicos, una secreta innovación tecnológica, un potencial capaz de estimular la creatividad del ilusionista. En síntesis, objetos inscriptos en un proyecto dirigido y avalado por el saber mágico, consagrado a profundizar la actividad en su conjunto.

Muchos productos que inundan los bazares de magia no son, en rigor de verdad, objetos mágicos, ya que están más próximos al juguete, al juego de ingenio, al chasco, al desafío topológico, o sea, pertenecen a la miscelánea del ilusionismo. El mercado mágico no escapa a la lógica de producción y consumo, y esta dinámica exige más de lo que la producción específica puede ofrecer en términos de calidad mágica.

De todas maneras, existe una inteligente utilización de diversos objetos que no están sujetos al proceso de diseño, fabricación y consumo. Elementos y utensilios que pueblan nuestra cotidianeidad son denegados en tanto función y valor e ingresados al dominio de lo mágico. 
Según sea su campo de procedencia, los objetos mágicos pueden clasificarse en tres grupos:

1. Objetos producidos por y para el ilusionismo, dispositivos precisos elaborados artesanalmente o en serie destinados a provocar un efecto, dos o tres a lo sumo, que satisfacen algunos de los principios mágicos ya mencionados: aparición-desaparición, transposición, restauración, penetración, transformación, levitación, adivinación y fenómenos antinaturales.

2. Objetos dotados de propiedades físicas permisivas. Forma, tamaño, densidad, elasticidad, entre otras cualidades, se combinan eficazmente para la función mágica. Objetos encontrados/ prestados, no programados para este fin pero cuyas características los vuelven competentes: monedas, pañuelos, billetes, cigarrillos, vasos.

3. Objetos que se ubican en un nivel intermedio entre los dos anteriores. Se trata de aquellas cosas halladas, pasibles de ser modificadas en secreto. Con esta mediación se convierten en objetos alterados con apariencia estable, por ejemplo, los naipes marcados.

Cada objeto impone una mecánica de uso, el ilusionista está obligado a crear la presentación adecuada a través de su proyecto estético, su técnica y su capacidad histriónica. La acción de mostrar una caja, que suponemos vacía, requiere de un escrupuloso cálculo espacial. Es justamente la forma, el funcionamiento y el grado de adulteración de la caja, si la hubiese, lo que exige programación espacial, precisión, cálculo temporal y táctica comunicativa.

Ilusionista, objetos, espacio y audiencia participan de un ritual espectacular y lúdico cuyo principio activo es la sustancia objetual. Sustancia que se le inocula perceptivamente al espectador que evalúa, sumariamente en un instante, todo lo sabido del objeto. Una especie de balanza conjetural pone en equilibrio todo lo que es y todo lo que no es ese objeto en tanto cualidades y posibilidades. Si la moneda es redonda, metálica, por lo tanto sólida y la mesa es cuadrada, de madera y sólida también, ¿cómo pudo la moneda atravesar la mesa? Para que el fenómeno sea efectivo dos mundos deben ser activados. Por un lado, el de la realidad empírica del objeto y, por el otro, el de la virtualidad de lo mágico. El objeto en el ilusionismo se presenta con todos sus atributos, ya se trate de objetos mínimos, como los usados en "micromagia", o de aparatos de tamaño considerable, como los usados de la especialidad "grandes ilusiones". Esta última categoría trabaja con cajas, cajones, baúles, o sea con artefactos demasiado voluminosos para ser considerados objetos aunque, por su agilidad de uso, son tentados a ingresar a la categoría específica.

Al mismo tiempo que presenta su estado mundano, el objeto en el ilusionismo representa, es decir, se vuelve a presentar en otro estado, con otras facultades, capaz de cumplir un destino inesperado: desmaterializarse, atravesar sólidos, bilocarse, entre otros prodigios. El objeto se convierte, así, en el protagonista de un proceso de virtualización, cambia su identidad y su localización terrenal. El espectador activa un procedimiento simple, el de la copresencia, que confronta lo real y lo virtual, dando valor probatorio a lo sucedido.

En condiciones favorables, el ilusionismo reformatea el objeto que pasa de una situación de normalidad a un estado de exaltación espectacular.

Queda claro que el espectador es cómplice de este juego cuyas reglas consisten en saber que, con habilidad y sutileza, algo se le oculta a la razón y se le escamotea a la percepción. 
No es riesgoso afirmar que pocas prácticas escénicas singularizan de tal manera lo objetual y espacial como el ilusionismo y, aún así, es notable que haya sido categorizada, junto a otras -malabarismo, equilibrismo, pantomima, por citar algunas- como actividad parateatral. Por mucho tiempo se tipificó como práctica periférica al teatro con mayúscula. La magia fue arrojada a una clasificación multiforme como es "artes del entretenimiento". Categoría tan genérica que recuerda a la noción de cajón donde van a parar las cosas olvidadas a la espera de que alguien las reclame.

El Diccionario de la Performance y del Teatro Contemporáneo, de Patrice Pavis, parece reclamarla reconociendo a la "Magia nueva" (2016:194) como un arte de pleno derecho que a partir de la década del noventa no deja de desarrollarse con autonomía.

La contemporaneidad, caracterizada por establecer puentes entre saberes que parecían incomunicables, crea modelos interdisciplinarios que abarcan campos antes segmentados como el científico, humanístico y artístico, entre otros. Estudios recientes concebidos en áreas de conocimiento como la psicología, la neuropsiquiatría o la teoría de la percepción, se valen del ilusionismo para ejemplificar el funcionamiento cerebral y las implicancias en la conducta humana. Algunos investigadores se arriesgan a formular una nueva categoría a la que bautizaron, al menos provisionalmente, Neuromagia.

El teatro de objetos hace ya algunas décadas que tiende a establecerse como un territorio teatral autónomo. Establece ciertos criterios disciplinares surgidos de las obras creadas e incluso, quizás lo más importante, se actualiza a partir de la problematización que supone el ingreso de nuevas tecnologías en relación al sujeto y las manifestaciones heterogéneas que surgen de las artes visuales. El teatro de objetos participa de la contemporaneidad artística definida por algunos rasgos tales como lo performativo, lo precario, la territorialización, lo radicante, la complejidad y la autoría compartida, entre otras características.

\section{Conclusión}

La escena mágica es un terreno particular para reactivar el universo objetual y todas sus facultades materiales. Definido el objeto en tanto dimensión, función y valor simbólico, el ilusionismo extrae otro valor adicional que pondera su capacidad de encantar. Una energía espectacular emana de las cosas a través de la operación mágica. El objeto es central en la estructura teatral cuyos componentes son sujeto, objeto, espacio. Desde ese vértice actúa como vector portador de intensidades concretas que modifican al ilusionista y a la escena. Cuando el objeto mágico, a través de sus creadores y usuarios, se asuma como receptor y partícipe de la creación contemporánea, quizás pueda problematizar al ilusionismo generando una estética transformadora. 


\section{Q Bibliografía}

"Alvarado, A. (2018). Cosidad, carnalidad y virtualidad: cuerpos y objetos en escena. Buenos Aires: UNA.

"Baudrillard, J. (2016). El sistema de los objetos. Buenos Aires: Siglo XXI.

"Ferrater M. José (200o). Diccionario de Filosofía abreviado. Buenos Aires: Sudamericana.

»Pavis, P. (2016). Diccionario de la performance y del teatro contemporáneo. Ciudad de México: Paso de Gato.

"Pavis, P. (2003). Diccionario del teatro: dramaturgia, estética, semiología. Ciudad Autónoma de Buenos Aires: Paidós. 